\title{
Cost of noninfectious comorbidities in patients with HIV
}

\author{
Giovanni Guaraldi' \\ Stefano Zona' \\ Marianna Menozzi' \\ Federica Carli' \\ Pietro Bagni' \\ Alessandra Berti ${ }^{2}$ \\ Elisa Rossi ${ }^{2}$ \\ Gabriella Orlando' \\ Giuliana Zoboli ${ }^{3}$ \\ Frank Palella ${ }^{4}$ \\ 'Department of Medical and Surgical \\ Sciences for Children \& Adults, \\ University of Modena and Reggio \\ Emilia, Modena, Italy; ${ }^{2}$ Health Care \\ Systems Department, CINECA \\ Consortium of Universities, Bologna, \\ Italy; ${ }^{3}$ nfectious Disease Clinic, \\ Arcispedale of Reggio Emilia, Reggio \\ Emilia, Italy; ${ }^{4}$ Division of Infectious \\ Diseases, Northwestern University, \\ Feinberg School of Medicine, Chicago, \\ IL, USA
}

Correspondence: Giovanni Guarald Department of Medical and Surgical Sciences for Children \& Adults University of Modena and Reggio Emilia, Via del Pozzo 7I, 4II 2 Modena, Italy Tel +395942 25318

Fax +395942 23710

Email giovanni.guaraldi@unimore.it
This article was published in the following Dove Press journal:

ClinicoEconomics and Outcomes Research

20 September 2013

Number of times this article has been viewed

Objectives: We hypothesized that the increased prevalence of noninfectious comorbidities (NICMs) observed among HIV-infected patients may result in increased direct costs of medical care compared to the general population. Our objective was to provide estimates of and describe factors contributing to direct costs for medical care among HIV-infected patients, focusing on NICM care expenditure.

Methods: A case-control study analyzing direct medical care costs in 2009. Antiretroviral therapy (ART)-experienced HIV-infected patients (cases) were compared to age, sex, and race-matched adults from the general population, included in the CINECA ARNO database (controls). NICMs evaluated included cardiovascular disease, hypertension, diabetes mellitus, bone fractures, and renal failure. Medical care cost information evaluated included pharmacy, outpatient, and inpatient hospital expenditures. Linear regression models were constructed to evaluate predictors of total care cost for the controls and cases.

Results: There were 2854 cases and 8562 controls. Mean age was 46 years and $37 \%$ were women. We analyzed data from 29,275 drug prescription records. Positive predictors of health care cost in the overall population: HIV infection $(\beta=2878$; confidence interval $(\mathrm{CI})=2001-3755)$; polypathology $(\beta=8911 ; \mathrm{CI}=8356-9466)$; age $(\beta=62 ; \mathrm{CI}=45-79)$; and ART exposure $(\beta=18,773 ; C I=17,873-19,672)$. Predictors of health care cost among cases: Center for Disease Control group $C(\beta=1548 ; C I=330-2766)$; polypathology $(\beta=11,081 ; C I=9447-12,716)$; age $>50$ years $(\beta=1903$; $C I=542-3264)$; protease inhibitor exposure (per month of use; $\beta=69 ; \mathrm{CI}=53-85)$; CD4 count $<200$ cells $/ \mathrm{mm}^{3}(\beta=5438 ; \mathrm{CI}=3082-7795)$; and ART drug change (per change; $\beta=911 ; C I=716-1106$ ).

Conclusion: Total cost of medical care is higher in cases than controls. Lower medical costs associated with higher CD4 strata are offset by increases in the care costs needed for advancing age, particularly for NICMs.

Keywords: pharmacoeconomics, HIV, antiretroviral therapy, noninfectious comorbidities

\section{Background}

HIV disease is the largest pandemic of the modern age and absorbs an enormous amount of health care resources. Estimates of the cost of treating HIV infection appeared soon after the availability of highly active antiretroviral therapy (ART) to prove cost efficacy of new drugs available in the late 1990s. ${ }^{1-3}$ These drugs were very costly but very convenient for health care systems due to the impact of ART in decreasing mortality and reducing hospital utilization. ${ }^{4-7}$

In the 1990s it became clear that CD4 cell count was not only a very sensitive surrogate marker of AIDS mortality, but also a major determinant of health care cost: the lower the CD4 the higher the direct cost of medical care. ${ }^{8,9}$ 
This result was also confirmed in a study of medical care cost for patients who present late $\left(\mathrm{CD} 4<200\right.$ cells $\left./ \mathrm{mm}^{3}\right)$ with HIV infection. These patients appeared to consume more than $200 \%$ higher care cost in the year following HIV diagnosis than patients who present with higher CD4. ${ }^{10}$

The clinical picture of HIV disease has changed rapidly in the last 10 years. Noninfectious comorbidities (NICMs) including cardiovascular disease (CVD), hypertension (Htn), bone fractures, renal failure, and diabetes mellitus (DM), became the most frequently observed causes of morbidity and mortality in HIV-infected patients. ${ }^{11-17}$ NICMs aggregate to give rise to complex polypathology pictures that typically occur in advanced age and describe geriatric syndromes. ${ }^{18-20}$ We hypothesized that the increased prevalence of NICMs observed among HIV-infected patients may result in increased direct cost of medical care in respect to the general population. ${ }^{21,22}$ It is necessary to update total cost of medical care in HIV in order to better predict resource and allocation needs for the care of people living with HIV (PLWHA).

Our objective was to provide estimates and determinants of direct cost of medical care for HIV-infected patients, including direct cost of NICMs.

\section{Methods}

This is a case-control study analyzing all direct medical costs in the 2009 calendar year.

Cases were ART-experienced HIV-infected patients $>18$ years of age who had access to the metabolic clinic of the University of Modena and Reggio Emilia, Modena, Italy.

This outpatient clinic is a multidisciplinary center for the management of NICMs in ART-experienced patients, as previously described. ${ }^{23}$ Patients attending this referral service are the patients attending the Modena HIV clinic as well as individuals referred from neighboring HIV centers.

Controls were matched according to age, sex, race, and geographical area and were selected from the CINECA ARNO observational database. ${ }^{24}$ The ARNO Observatory is an online, multicenter, observational database in which population-based data is collected and epidemiological methods are used to combine and aggregate huge volumes of health and health care-related data for each individual patient. These data include primary care provider-generated medication prescriptions, records from hospital admissions and discharges, diagnostic laboratory tests, and radiographic examinations. This information is linked to other sources of patient data (including vital statistics and patient demographics) in order to construct a tool that is used to provide comprehensive tracking of clinical diagnoses and health care use trends throughout Italy. The ARNO observatory has been active since 1986 and includes health care prescription data generated by 8300 general practitioners for a population of 11 million persons cared for at 32 health units in Italy. The database is updated monthly.

\section{Direct health care cost analysis}

Direct health care cost was retrospectively analyzed in the 2009 calendar year using the following indicators:

1. Hospitalization cost: calculated by collecting International Classification of Diseases (ICD)-9 codes in cases and controls. All hospitalization with a primary or secondary ICD-9 comorbidity diagnosis code, including CVD, Htn, $\mathrm{DM}$, bone fractures, and renal failure diagnosis, were selected. $^{25}$

2. Outpatient HIV medical care cost. With the movement of HIV care into the outpatient setting, it was no longer possible to evaluate the cost of medical care using ICD-9 codes, therefore we decided to attribute a mean patient care cost obtained by the most recent reference value able to better define HIV-related care cost in patients with ART. This estimate is adjusted for current CD4 count strata and, in particular, it accounts for US\$1,381/ year for patients with CD4 $<75$ cells $/ \mathrm{mm}^{3}$, US\$1,241/ year for $76<\mathrm{CD} 4<200$ cells $/ \mathrm{mm}^{3}$ and US\$190/year for $\mathrm{CD} 4>201$ cells $/ \mathrm{mm}^{3} .^{26}$

3. NICM medication cost: calculated using pharmaceutical tracing by average wholesale prices obtained by the Agenzia Italiana del Farmaco (AIFA) national pharmaceutical handbook. ${ }^{27}$

4. ART medication cost: calculated using pharmaceutical tracing, by average hospital sale price.

Total cost is defined as the sum of mean of NICM costs plus mean of HIV hospitalization costs plus mean of drug costs.

For the purpose of this study, the following NICM conditions were eligible for the assessment of direct cost: CVD, Htn, DM, bone fractures, and renal failure. ICD-9 hospital codes and drug tracing criteria were used to identify NICM diagnoses and direct medical cost in the study population. Polypathology (Pp) was defined as the simultaneous presence of two or more NICMs. ${ }^{28}$

The category of CVD included the following diagnoses: myocardial infarction, coronary artery disease, peripheral vascular disease, stroke, angina pectoris, coronary artery bypass grafting, and angioplasty.

In cases, the following HIV-specific variables were collected from patient charts: 
- Cumulative exposure to nonnucleoside reverse transcriptase inhibitors (NNRTIs), nucleoside RTIs (NRTIs), and protease inhibitors (PIs)

- Number of previous ART drug switch before the current regimen

- Current CD4 $<200 / \mathrm{mm}^{3}$

- Age categories "young" and "old," using 50 years as the cutoff age

- HIV viral load was categorized as undetectable if $<40$ copies/mL

- Previous AIDS diagnosis was defined according to the Centers for Disease Control and Prevention (CDC) group "C" category. ${ }^{29}$

\section{Statistical analysis}

Comparisons of variables considered in our study, performed between groups and among age strata, were analyzed using $\chi^{2}$-test for categorical variables and $t$-test or analysis of variance (ANOVA) for continuous variables. $P$-value $<0.05$ was considered significant. Post hoc analyses were performed using Bonferroni's adjustment and significance level was considered for $P<0.008$.

Considering the non-normal distribution of total costs, generalized linear models (GLMs) were constructed to evaluate independent factors associated with total cost in the whole population and in the subgroup of HIV-infected patients, using inverse Gaussian family distribution.

In the regression analysis in the HIV-positive cohort, age was stratified using the threshold of 50 years to evaluate the effect of aging on total cost.
The variables for regression analyses were chosen on the basis of their clinical relevance.

Statistical analyses were conducted using the Intercooled STATA software package, version 12.1 for Mac (StataCorp LP, College Station, TX, USA).

\section{Results}

There were 2854 cases and 8562 controls included in the analysis; 4244 (37\%) were women; the mean age of the overall population was $46( \pm 8)$ years.

Among cases, the median duration of HIV infection was 196 months (range 36-248), median CD4 nadir was 170 (interquartile range [IQR] 66-263.5), median current CD4 was 520 (IQR 374-702). Plasma HIV RNA levels were below the limit of quantification in 1825 cases $(71.3 \%)$. The cumulative NRTI, NNRTI, and PI exposures were 116 (IQR 72-155), 37 (IQR 16-70), and 55 (IQR 29-88) months, respectively. A CD4 nadir $<200$ was documented in $1525(57.5 \%)$ cases. Twenty-nine thousand and two-hundred seventy-five $(29,275)$ drug records were analyzed.

Figure 1 shows the comparative prevalence of NICMs and Pp observed in 2009 among HIV-infected versus (vs) uninfected patients, stratified by age. A significantly higher prevalence of renal failure, bone fractures, and DM was observed in HIV-infected patients compared to controls in all age strata. Across all age strata, Pp prevalence was significantly higher in cases compared to controls (all $P$-values $<0.001$ ).

Pp prevalence in cases aged 41-50 years was nonstatistically different from the prevalence observed in controls aged $51-60$ years $(9.09 \%$ vs $6.61 \% ; P=0.010)$,

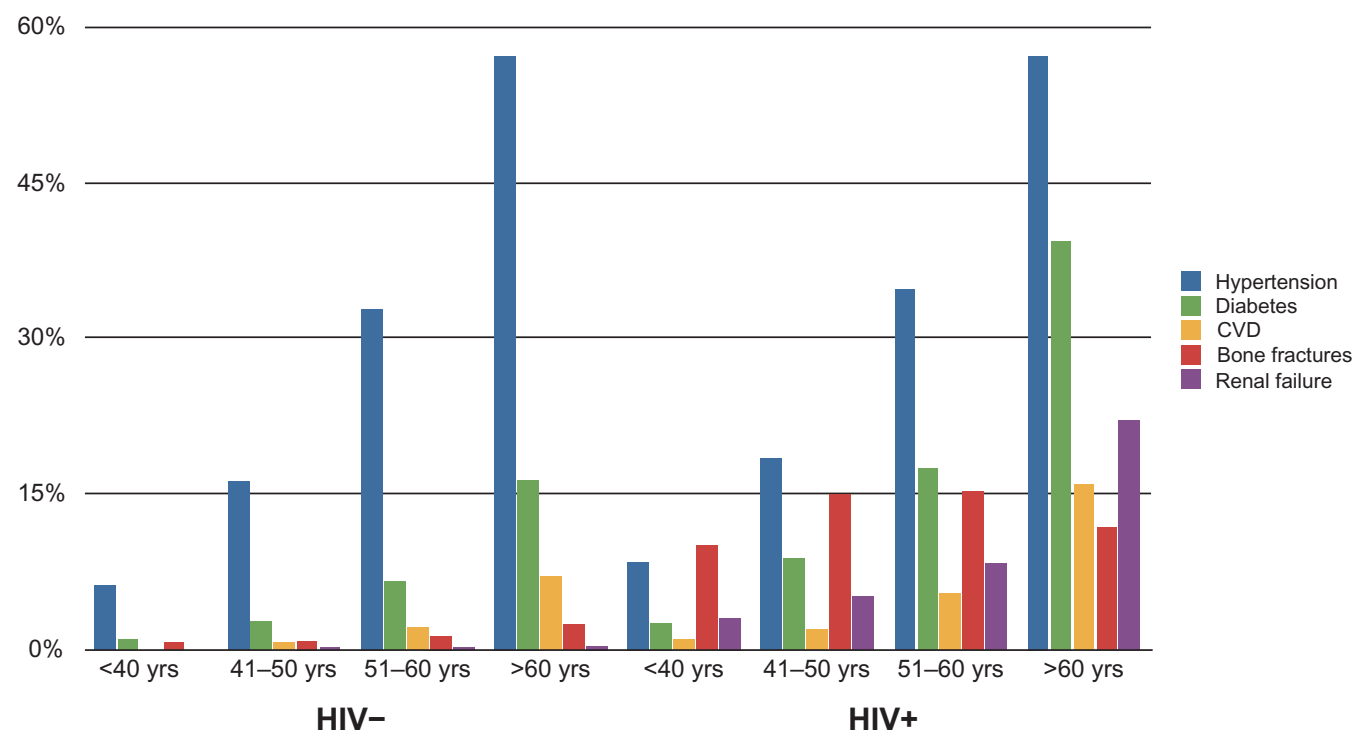

Figure I Comparative risk of hypertension, diabetes, cardiovascular disease (CVD), fracture, and renal failure, by age strata, among cases and controls. 
resulting in an "anticipated" effect of Pp prevalence of almost 10 years in cases compared to controls.

The anticipated effect of 10 years in $\mathrm{Pp}$ prevalence resulted in a parallel anticipated effect of 20-30 years in total direct cost: the mean total direct cost spent in cases aged less than 40 years was nonstatistically different from the total cost spent in controls aged more than 60 years (US\$1,968.53 vs US\$2,783.38; $P=0.615$ ).

In order to give better insight to the major determinants of medical cost, Figure 2 compares the direct cost of HIV outpatient, and ART and NICM. Increased age was associated with increased direct cost of NICM both in cases and controls $(P<0.001)$.

In cases only, total direct cost was compared in young and old HIV-infected patients stratified for low and high CD4 counts. The total annual cost of medical care for HIV-infected patients younger than 50 years and with CD $4<200$ cells $/ \mathrm{mm}^{3}$ was not significantly different to the total annual cost of medical care for HIV-infected patients older than 50 years and with CD4 > 200 cells $/ \mathrm{mm}^{3}$ (US\$16,614 vs US\$14,061; $P=0.244)$. Total annual direct cost of HIV-infected patients older than 50 years and with CD $<200$ cells $/ \mathrm{mm}^{3}$ was the highest of the group comparisons (US\$14,061) (Figure 3).
A linear regression model was built to identify independent predictors of total cost in the whole population (Table 1). Predictors of total cost were: HIV infection $(\beta=1.10$; confidence interval $(\mathrm{CI})=1.09-1.11) ; \mathrm{Pp}(\beta=0.90$; $\mathrm{CI}=0.898-0.899)$; age $(\beta=0.016 ; \mathrm{CI}=0.016-0.016)$; ART exposure $(\beta=1.594 ; \mathrm{CI}=1.591-1.596)$; and male sex $(\beta=0.018 ; \mathrm{CI}=0.018-0.019)$.

A second linear regression model was built to identify independent predictors of total cost in HIV-infected patients only (Table 2).

Predictors of total cost in cases were: CDC group $\mathrm{C}$ $(\beta=0.069 ; \mathrm{CI}=0.069-0.070) ; \mathrm{Pp}(\beta=0.667 ; \mathrm{CI}=0.666-0.668)$; age $>50$ years $(\beta=0.108 ; \mathrm{CI}=0.107-0.109)$; male sex $(\beta=0.017$; CI $=0.016-0.018) ;$ PI exposure per month $(\beta=0.003 ; \mathrm{CI}=0.003-0.003) ; \mathrm{CD} 4<200(\beta=0.233 ;$ $\mathrm{CI}=0.232-0.234)$; according to number of ART switch $(\beta=0.022 ; \mathrm{CI}=0.022-0.022)$.

\section{Discussion}

At least 3.0 million years of life have been saved in the United States as a direct result of care of patients with AIDS, highlighting the significant advances made in HIV disease treatment. ${ }^{30}$ This survival benefit greatly exceeds

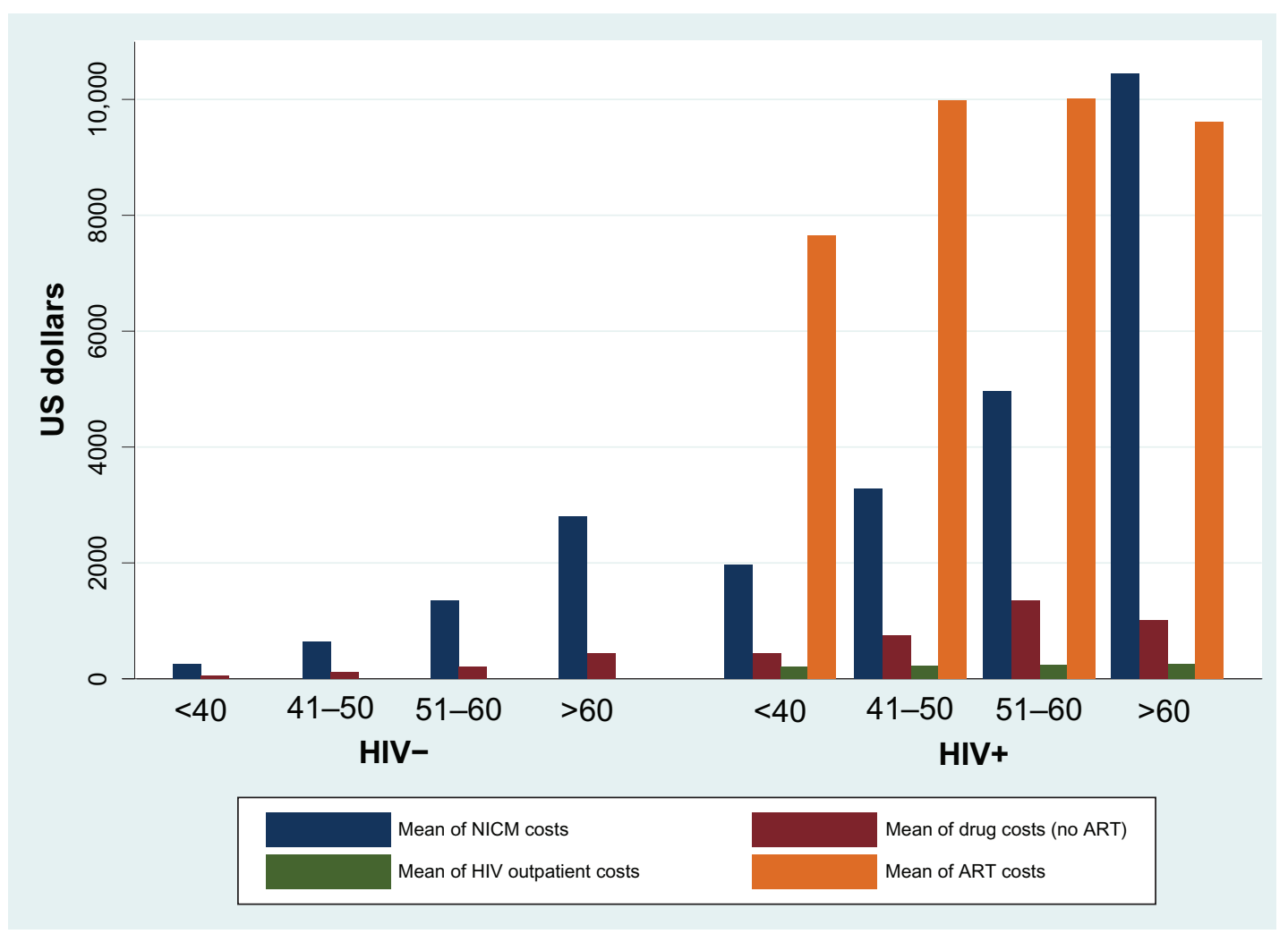

Figure 2 Total cost of medical care in cases and controls stratified by age decades. Abbreviations: ART, antiretroviral therapy; NICM, noninfectious comorbidity. 


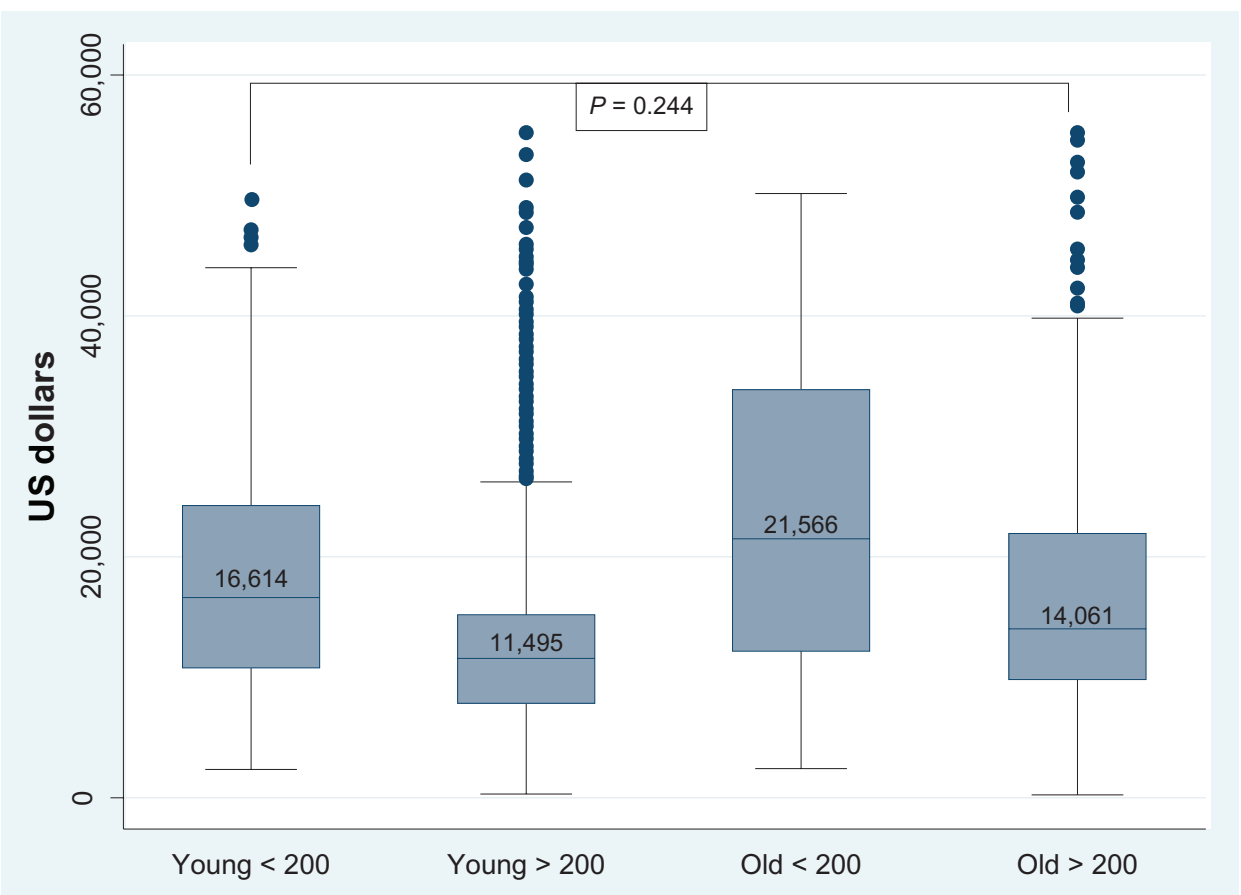

Figure 3 Comparison between the cost of medical care for HIV-infected patients younger than 50 years with CD4 200 cells $/ \mathrm{mm}^{3}$ and older than 50 years with CD4 $>200$ cells $/ \mathrm{mm}^{3}$.

that achieved for patients with many other chronic diseases in the US, but its immediate consequence is an expected increase in cost of medical care due to longer survival of PLWHA on ART. ${ }^{30-36}$ This survival increase implies not only longer cumulative exposure of ART per single patient but also an increase in cost secondary to age-related diseases, as previously described in the general population. ${ }^{37}$ Moreover, these clinical conditions, aggregating in $\mathrm{Pp}$, appear to occur at a younger age in HIV-infected patients, causing a "premature aging process" 38 in these patients, as previously demonstrated in the same cohort but with a 7-year period of observation. $^{23,38}$

The present study aimed to provide estimates and determinants of direct cost of HIV care in the ART era.

With regards to estimates, we were able to demonstrate that the total direct cost increases two-fold moving from the $<40$

Table I Multivariable regression analysis of independent factors associated with total cost in HIV-infected patients

\begin{tabular}{|c|c|c|c|}
\hline & $\beta$ coefficient & $95 \% \mathrm{Cl}$ & $P$-value \\
\hline Male sex & 0.018 & $0.018-0.019$ & $<0.001$ \\
\hline Age & 0.016 & $0.016-0.016$ & $<0.001$ \\
\hline Polypathology & 0.90 & $0.898-0.899$ & $<0.001$ \\
\hline HIV infection & 1.10 & I.09-I.II & $<0.001$ \\
\hline ART assumption & $\mathrm{I} .594$ & $1.59 \mid-1.596$ & $<0.001$ \\
\hline
\end{tabular}

Abbreviation: ART, antiretroviral therapy; $\mathrm{Cl}$, confidence interval. years age strata of HIV-infected patients (US\$10,588.45) to those older than 60 years (US\$21,280.72).

In order to make total direct cost estimates more generalizable, we stratified cost on age categories (young vs old) and traditional immunological markers of HIV disease $\left(\mathrm{CD} 4<200\right.$ vs $>200$ cells $\left./ \mathrm{mm}^{3}\right)$. ${ }^{39}$ We confirmed that CD4 count is a powerful indicator of the burden of care costs; in fact inpatient costs increase as patients become more immunosuppressed..$^{21,40}$ Nevertheless, this indicator did not appear to change across age strata. On the contrary, the

Table 2 Multivariable regression analysis of independent factors associated with total cost in HIV-infected patients

\begin{tabular}{|c|c|c|c|}
\hline & $\beta$ coefficient & $95 \% \mathrm{Cl}$ & $P$-value \\
\hline Male sex & 0.017 & $0.016-0.018$ & $<0.001$ \\
\hline Age $>50$ years & 0.108 & $0.107-0.109$ & 0.002 \\
\hline Current CD4 less than & 0.233 & $0.232-0.234$ & $<0.00$ I \\
\hline \multicolumn{4}{|l|}{200 cells $/ \mathrm{mm}^{3}$} \\
\hline CDC C category ${ }^{29}$ & 0.069 & $0.069-0.070$ & $<0.00$ I \\
\hline Polypathology & 0.667 & $0.666-0.668$ & $<0.00$ I \\
\hline NRTI exposure, months & -0.0004 & $-0.0004 ;-0.0004$ & $<0.00$ I \\
\hline NNRTI exposure, months & 0.0006 & $0.0005-0.0006$ & $<0.001$ \\
\hline PI exposure, months & 0.003 & $0.003-0.003$ & $<0.00 \mathrm{I}$ \\
\hline $\begin{array}{l}\text { Number of therapy } \\
\text { switches }\end{array}$ & 0.022 & $0.022-0.022$ & $<0.001$ \\
\hline
\end{tabular}

Abbreviations: CDC, Centers for Disease Control and Prevention; NNRTI, nonnucleoside reverse transcriptase inhibitors; NRTI, nucleoside reverse transcriptase inhibitors; Pl, protease inhibitor; $\mathrm{Cl}$, confidence interval. 
driving determinant of the age-related effect was the direct cost of NICMs.

Chen et al, in a study analyzing distribution of health care expenditures for HIV-infected patients in the early ART era, but did not take into account the costs derived from toxicities or comorbidities. ${ }^{40}$ They stated that this exclusion was unlikely to have a major impact on the analysis of care cost. The current scenario in the advanced ART era is much changed. It is now clear that NICMs are not simply the result of direct ART toxicity but rather a complex interplay of host virus and drug-risk factors resulting in $\mathrm{Pp}$ and translating to a premature aging process affecting HIV-infected patients. ${ }^{20,41-43}$ It is quite striking that, in the logistic regression analyses, Pp accounted for a cost expenditure three times higher than that of HIV infection per se.

\section{Summary}

The key points of this study are:

1. The total cost of medical care is higher in HIV-infected patients than in the general population in any age strata. This issue is quite obvious, given that ART medication cost accounts for the majority of the total care cost. $3,21,44$ This cost did not appear to vary across age groups. Besides that, we were also able to demonstrate that NICM care costs contributed significantly to this higher cost burden of HIV-infected patients in the context of a premature aging process producing an anticipation effect of more than 20 years in total direct cost. This study was able to demonstrate that the premature aging process affecting HIV-infected patients translates to a premature cost expenditure in this population. We believe it is necessary to continue to monitor in prospective studies the impact of the HIV-specific accelerated aging process on total care cost. Pp accounts for a cost expenditure three times higher than that of HIV infection per se (US\$8,911 vs US\$2,878).

2. The reduction of total care cost observed in the increasing CD4 strata was compensated by the increase of the total care cost observed across age strata.

3. Focusing on independent predictors of total cost in HIVinfected patients, we confirmed that low CD4 cell count and $\mathrm{CDC}$ group $\mathrm{C}$ play a relevant role with regard to health care expenditure. This should reinforce what has already been suggested by Krentz and Gill, that early initiation of ART may result in a cost-saving intervention. ${ }^{26}$ Previous ART exposure accounted for a low proportion of increase cost that resulted as significant only for PIs. On the contrary the number of therapy switches represented a good indicator of increased cost of ART, presumably due to mega-ART combination and use of newer and more costly drugs.

We therefore believe that, in an epidemiological situation in which the majority of PLWHA will be older than 50 years by the year 2015 , health care providers may expect an increase in total care cost for the HIV-infected population. ${ }^{21,47,48}$

\section{How will the health care system be able to face this changing scenario?}

Where possible, the cost of HIV treatment and care needs to be reduced without reducing the quality of services, and, once again, we need to stress that prevention programs need to become more effective. ${ }^{44}$

While high-income countries are struggling to meet these increasing costs, middle- and lower-income countries with larger epidemics are likely to find it even more difficult to meet these increasing demands, given that they have fewer resources. $^{48}$

\section{Limitations}

This study has several limitations, unavoidable in the crosssectional nature of its design. We provided drug cost values in dollars for the purpose of an international interpretation of the results. Nevertheless, we need to underline that any pharmacoeconomic analysis must be strictly contextualized in the setting in which it was generated.

As previously shown, the metabolic clinic setting, despite being a referral service, still continues to be representative of HIV outpatients living in northern Italy, given that the prevalence of NICMs was not different between the metabolic clinic cohort and the Modena HIV cohort. $^{38}$

We firmly believe that a better knowledge of health care determinants will allow for a better allocation of health care resources.

\section{Conclusion}

What we have observed in this study is that the total cost of medical care is higher in HIV-infected patients in comparison with HIV-negative controls. Lower medical costs associated with higher CD4 strata are offset by increases in the care costs needed for advancing age, particularly for NICMs.

\section{Disclosure}

The authors report no conflicts of interest in this work. 


\section{References}

1. Scitovsky AA, Rice DP. Estimates of the direct and indirect costs of acquired immunodeficiency syndrome in the United States, 1985, 1986, and 1991. Public Health Rep. 1987;102(1):5-17.

2. Scitovsky AA, Cline M, Lee PR. Medical care costs of patients with AIDS in San Francisco. JAMA. 1986;256(22):3103-3106.

3. Bozzette SA, Joyce G, McCaffrey DF, et al; HIV Cost and Services Utilization Study Consortium. Expenditures for the care of HIV-infected patients in the era of highly active antiretroviral therapy. $N$ Engl J Med. 2001;344(11):817-823.

4. Palella FJ Jr, Delaney KM, Moorman AC, et al. Declining morbidity and mortality among patients with advanced human immunodeficiency virus infection. HIV Outpatient Study Investigators. $N$ Engl $J$ Med. 1998;338(13):853-860.

5. Moore RD, Chaisson RE. Natural history of HIV infection in the era of combination antiretroviral therapy. AIDS. 1999;13(14):1933-1942.

6. Torres RA, Barr M. Impact of combination therapy for HIV infection on inpatient census. N Engl J Med. 1997;336(21):1531-1532.

7. Gonzalo T, Garcia Goni M, Munoz-Fernandez MA. Socio-economic impact of antiretroviral treatment in HIV patients. An economic review of cost savings after introduction of HAART. AIDS Rev. 2009; 11(2):79-90.

8. Gebo KA, Chaisson RE, Folkemer JG, Bartlett JG, Moore RD. Costs of HIV medical care in the era of highly active antiretroviral therapy. AIDS. 1999;13(8):963-969.

9. Hill A, Hemmett L, Wilson B. Analysis of costs by CD4 count category for the darunavir/r $600 / 100 \mathrm{mg}$ bid and control protease inhibitor arms of the POWER 1 and 2 trials. HIV Clin Trials. 2007; 8(5):303-310.

10. Krentz HB, Auld MC, Gill MJ. The high cost of medical care for patients who present late (CD4 $<200$ cells/microL) with HIV infection. HIV Med. 2004;5(2):93-98.

11. Phillips AN, Neaton J, Lundgren JD. The role of HIV in serious diseases other than AIDS. AIDS. 2008;22(18):2409-2418.

12. Weber R, Sabin CA, Friis-Møller N, et al. Liver-related deaths in persons infected with the human immunodeficiency virus: the D:A:D study. Arch Intern Med. 2006;166(15):1632-1641.

13. Justice AC. Prioritizing primary care in HIV: comorbidity, toxicity, and demography. Top HIV Med. 2006;14(5):159-163.

14. Sackoff JE, Hanna DB, Pfeiffer MR, Torian LV. Causes of death among persons with AIDS in the era of highly active antiretroviral therapy: New York City. Ann Intern Med. 2006;145(6):397-406.

15. Deeks SG, Phillips AN. HIV infection, antiretroviral treatment, ageing, and non-AIDS related morbidity. BMJ. 2009;338:a3172.

16. Shah SS, McGowan JP, Smith C, Blum S, Klein RS. Comorbid conditions, treatment, and health maintenance in older persons with human immunodeficiency virus infection in New York City. Clin Infect Dis. 2002;35(10):1238-1243.

17. Vance DE, Mugavero M, Willig J, Raper JL, Saag MS. Aging with HIV: a cross-sectional study of comorbidity prevalence and clinical characteristics across decades of life. JAssoc Nurses AIDS Care. 2011; 22(1):17-25.

18. Justice AC. HIV and aging: time for a new paradigm. Current HIV/ AIDS Rep. 2010;7(2):69-76.

19. Fried LP, Tangen CM, Walston J, et al; Cardiovascular Health Study Collaborative Research Group. Frailty in older adults: evidence for a phenotype. J Gerontol A Biol Sci Med Sci. 2001;56(3):M146-M156.

20. Goulet JL, Fultz SL, Rimland D, et al. Aging and infectious diseases: do patterns of comorbidity vary by HIV status, age, and HIV severity? Clin Infect Dis. 2007;45(12):1593-1601.

21. Gebo KA, Fleishman JA, Conviser R, et al; HIV Research Network. Contemporary costs of HIV healthcare in the HAART era. AIDS. 2010; 24(17):2705-2715.

22. Grabar S, Weiss L, Costagliola D. HIV infection in older patients in the HAART era. J Antimicrob Chemother. 2006;57(1):4-7.

23. Guaraldi G, Zona S, Alexopoulos N, et al. Coronary aging in HIVinfected patients. Clin Infect Dis. 2009;49(11):1756-1762.
24. ARNO Osservatorio [database on the Internet]. CINECA. Available from: http://osservatorioarno.cineca.org. Accessed January 17, 2012. Italian.

25. International Classification of Diseases (ICD): 9th revision, basic tabulation list with alphabetic index. Geneva: World Health Organization; 1978. Available from: http://www.cdc.gov/nchs/icd/icd9. htm. Accessed May 31, 2013.

26. Krentz HB, Gill MJ. Cost of medical care for HIV-infected patients within a regional population from 1997 to 2006. HIV Med. 2008; 9(9):721-730.

27. Agenzia Italiana del Farmaco (AIFA) [homepage on the Internet]. Available from: http://www.agenziafarmaco.gov.it/. Accessed January 17, 2012.

28. Topinková E. Aging, disability and frailty. Ann Nutr Metab. 2008; 52(1):6-11.

29. Revised classification system for HIV infection and expanded surveillance case definition for AIDS among adolescents and adults [webpage on the Internet]. Atlanta, GA: Centers for Disease Control and Prevention (CDC); 1993. Available from: hhttp://www.cdc.gov/ mmwr/preview/mmwrhtml/00018871.htm. Accessed May 31, 2013.

30. Walensky RP, Paltiel AD, Losina E, et al. The survival benefits of AIDS treatment in the United States. J Infect Dis. 2006;194(1):11-19.

31. Berthelot JM, Will BP, Evans WK, Coyle D, Earle CC, Bordeleau L. Decision framework for chemotherapeutic interventions for metastatic non-small-cell lung cancer. J Natl Cancer Inst. 2000; 92(16):1321-1329.

32. Norum J. Adjuvant cyclophosphamide, methotrexate, fluorouracil (CMF) in breast cancer - is it cost-effective? Acta Oncol. 2000;39(1):33-39.

33. Rosamond WD, Chambless LE, Folsom AR, et al. Trends in the incidence of myocardial infarction and in mortality due to coronary heart disease, 1987 to 1994. N Engl J Med. 1998;339(13):861-867.

34. Kuntz KM, Tsevat J, Goldman L, Weinstein MC. Cost-effectiveness of routine coronary angiography after acute myocardial infarction. Circulation. 1996;94(5):957-965.

35. Weintraub WS, Mahoney EM, Lamy A; CURE Study Investigators. Long-term cost-effectiveness of clopidogrel given for up to one year in patients with acute coronary syndromes without ST-segment elevation. J Am Coll Cardiol. 2005;45(6):838-845.

36. Beck EJ, Mandalia S, Youle M, et al. Treatment outcome and costeffectiveness of different highly active antiretroviral therapy regimens in the UK (1996-2002). Int J STD AIDS. 2008;19(5):297-304.

37. de Meijer C, Koopmanschap M, D’Uva TB, van Doorslaer E. Determinants of long-term care spending: age, time to death or disability? J Health Econ. 2011;30(2):425-438.

38. Guaraldi G, Orlando G, Zona S, Menozzi M, Carli F, Garlassi E, et al. Premature Age-Related Comorbidities Among HIV-Infected Persons Compared With the General Population. Clin Infect Dis. 2011;53(11)1120-1126.

39. Levy AR, James D, Johnston KM, et al. The direct costs of HIV/AIDS care. Lancet Infect Dis. 2006;6(3):171-177.

40. Chen RY, Accortt NA, Westfall AO, et al. Distribution of health care expenditures for HIV-infected patients. Clin Infect Dis. 2006; 42(7):1003-1010.

41. Deeks SG. Immune dysfunction, inflammation, and accelerated aging in patients on antiretroviral therapy. Top HIV Med. 2009;17(4):118-123.

42. Kirk JB, Goetz MB. Human immunodeficiency virus in an aging population, a complication of success. J Am Geriatr Soc. 2009; 57(11):2129-2138.

43. Effros RB, Fletcher CV, Gebo K, et al. Aging and infectious diseases: workshop on HIV infection and aging: what is known and future research directions. Clin Infect Dis. 2008;47(4):542-553.

44. Magoni M, Scarcella C, Vassallo F, et al. The evolving burden of HIV infection compared with other chronic diseases in northern Italy. HIV Med. 2011;12(3):129-137.

45. Strategies for Management of Antiretroviral Therapy (SMART) Study Group; El-Sadr WM, Lundgren JD, Neaton JD, et al. CD4+ countguided interruption of antiretroviral treatment. $N$ Engl J Med. 2006; 355(22):2283-2296. 
46. When To Start Consortium; Sterne JA, May M, Costagliola D, et al. Timing of initiation of antiretroviral therapy in AIDS-free HIV-1infected patients: a collaborative analysis of 18 HIV cohort studies. Lancet. 2009;373(9672):1352-1363.

47. Luther VP, Wilkin AM. HIV infection in older adults. Clin Geriatr Med. 2007;23(3):567-583, vii.
48. Mandalia S, Mandalia R, Lo G, et al; NPMS-HHC Steering Group. Rising population cost for treating people living with HIV in the UK, 1997-2013. PLoS One. 2010;5(12):e15677.

\section{Publish your work in this journal}

ClinicoEconomics \& Outcomes Research is an international, peerreviewed open-access journal focusing on Health Technology Assessment, Pharmacoeconomics and Outcomes Research in the areas of diagnosis, medical devices, and clinical, surgical and pharmacological intervention. The economic impact of health policy and health systems organization also constitute important areas of coverage. The manuscript management system is completely online and includes a very quick and fair peer-review system, which is all easy to use. Visit http://www.dovepress.com/testimonials.php to read real quotes from published authors.

Submit your manuscript here: http://www.dovepress.com/clinicoeconomics-and-outcomes-research-journal 